\title{
Features of Atmospheric Pollutant in Beijing Region from 2014 to 2017
}

\author{
Tang Xiru ${ }^{1,}$, , Xu Liping ${ }^{1}$, Liu Shufu ${ }^{2}$, Shen Chunming ${ }^{1}$, Wang Bin ${ }^{1}$, Long Tao ${ }^{1}$ \\ ${ }^{1}$ Beijing Research Center of Urban System Engineering, Beijing, China \\ ${ }^{2}$ Institute of Remote Sensing and Digital Earth Chinese Academy of Sciences, Beijing, China

\section{Email address:} \\ lilihuo@yeah.net (Tang Xiru),911796246@qq.com (Xu Liping), liusf01@radi.ac.cn (Liu Shufu), \\ Chunming_Shen@126.com (Shen Chunming), Jadey2005@126.com (Wang Bin), veromcal@163.com (Long Tao) \\ ${ }^{*}$ Corresponding author
}

\section{To cite this article:}

Tang Xiru, Xu Liping, Liu Shufu, Shen Chunming, Wang Bin, Long Tao. Features of Atmospheric Pollutant in Beijing Region from 2014 to 2017. Science Discovery. Vol. 7, No. 2, 2019, pp. 98-106. doi: 10.11648/j.sd.20190702.18

Received: April 9, 2019; Accepted: May 20, 2019; Published: May 23, 2019

\begin{abstract}
In order to find effective ways to control atmospheric environment, this paper mainly studies the Spatial-temporal features of atmospheric pollutant distribution in the past 2014-2017 years. The particulate matter concentration was retrieved by remote sensing data and all data would be processed by Kriging method. The results show that most pollutant concentration decreased, especially $\mathrm{SO}_{2}, \mathrm{PM}_{2.5}$ and $\mathrm{PM}_{10}$, though the ozone problem is beginning to stand out; In addition, $\mathrm{CO}$ concentration in different regions varies in different seasons, meanwhile other pollutants do not like this.
\end{abstract}

Keywords: Atmospheric Pollutant, Inversion, Kriging, Remote Sensing Data, Spatial-Temporal Features

\section{4-2017年北京城区大气污染物浓度特征分析}

\author{
唐夕茹 $^{1^{*}}$, 徐丽萍 ${ }^{1}$, 柳树福 ${ }^{2}$, 沈春明 ${ }^{1}$, 王玢 ${ }^{1}$, 隆涛 $^{1}$ \\ ${ }^{1}$ 北京城市系统工程研究中心, 北京, 中国 \\ 2中国科学院遥感与数字地球研究所, 北京, 中国
}

\section{邮箱}

lilihuo@yeah.net (唐夕茹),911796246@qq.com (徐丽萍), liusf01@radi.ac.cn (柳树福), Chunming_Shen@126.com（沈春明）， Jadey2005@126.com(王玢), veromcal@163.com(隆涛)

摘要：为研究近年来北京城区大气污染物浓度时空变化规律，支撑北京市区域空气质量达标管理，本文利用数据反演 和克里金插值方法, 以遥感影像数据和地面气象站监测数据为基础, 深入分析2014年-2017年北京城区的主要污染物浓 度特征。通过分析发现, 北京城区大多数污染物浓度有下降趋势, 特别是 $\mathrm{SO}_{2} 、 \mathrm{PM}_{2.5}$ 和 $\mathrm{PM}_{10}$ 下降趋势显著, 但臭氧问 题开始突出; 此外, 不同区县的CO浓度的存在季节性差异，其他污染物浓度的空间差异对季节性不敏感。

关键词: 大气污染, 反演, 克里金差值, 遥感数据, 时空特征 


\section{1. 引言}

随着我国社会经济快速发展, 空气质量成为近年来人 们关注的焦点。以高浓度 $\mathrm{PM}_{10} 、 \mathrm{PM}_{2.5}$ 为特征的雾皬污染 在全国范围内频发, 在京津冀地区尤为显著 [1], 而北京作 为中国的政治中心、文化中心和国际交往中心，大气污染 治理与防治及其重要。

客观地评价空气质量的变化趋势, 可为有效的预报、 控制和治理大气污染提供参考和依据[2]。由于直接观测数 据的严重匿乏给 $\mathrm{PM}_{2.5}$ 分布规律和扩散模式的研究带来极 大困难, 于是利用 $\mathrm{PM}_{2.5}$ 与大气气溶胶的关系建立物理或 统计模型, 使用气溶胶卫星遥感反演产品来间接估算颗粒 物浓度成为早期研究热点 $[3,4]$ 。Wang[5]和Donkelaar [6]等 人对MODIS AOD与地面监测的 $\mathrm{PM}_{2.5}$ 浓度值进行相关性 研究。20世纪 80 年代中期, 国内学者开始利用遥感影像数 据分析大气特征[7], 首先开展的就是对气溶胶光学厚度的 反演和大气污染物质量浓度分析以及他们之间的联系研 究。刘大锰 $[8]$ 等从气溶胶质量浓度的日变化以及一个季节 里的变化特征出发,研究了颗粒物的质量浓度与各种气象 条件的对应关系。顾吉林[9]进行了大连市大气污染物质量 浓度与气溶胶光学厚度的相关性分析。

近年来空气质量指数开始官方发布后, 许多学者开始 利用该指标评估区域的空气质量, 李慧杰 $[10]$ 等人基于统 计学方法分析了京津冀地区空气质量指数的特征变化。王 斌[11]利用聚类分析法对我国不同城市的API进行分析。 李祥[12]等人利用自然正交函数分析了北京市空气质量及 其影响因素。

空气质量指数是一个综合性指标, 本文希望从不同大 气污染物角度出发, 利用数据反演和克里金插值方法, 以 遥感影像数据和地面气象站监测数据为基础, 深入分析 2014年-2017年北京城区（包括海淀区、朝阳区、东城区、 西城区、石景山区和丰台区 $)$ 的主要污染物 $\left(\mathrm{O}_{3} 、 \mathrm{SO}_{2}\right.$ 、 $\mathrm{NO}_{2} 、 \mathrm{CO} 、 \mathrm{PM}_{2.5}$ 和 $\left.\mathrm{PM}_{10}\right)$ 浓度特征, 挖掘污染物浓度的 时间和空间变化规律, 以期为北京市区域空气质量达标管 理提供可靠的科学依据。

\section{2. 研究方法}

\section{1. 数据来源}

本文用于分析颗粒物浓度的数据为2014-2017年的 MODIS数据, 数据采用Lambert投影坐标系, 空间分辨率 为 $3 \mathrm{~km}$ 。北京市空气质量数据来源于北京市 35 个监测站点 气象数据, 选取2014年1月-2017年12月间逐日数据。

\section{2. 数据处理方法}

对于颗粒物 $\left(\mathrm{PM}_{2.5}\right.$ 和 $\left.\mathrm{PM}_{10}\right)$ 的浓度处理, 本文利用 MODIS季度数据产品进行反演, 构建气溶胶光学厚度 (AOD) 与颗粒物浓度的关系。

由于 $\mathrm{PM}_{2.5}$ 和 $\mathrm{PM}_{10}$ 浓度的测定一般首先通过一个干燥 的过程, 结果代表比较固定相对湿度下的质量浓度情况。 而气溶胶光学厚度的遥感是在环境背景下进行, 气溶胶颗 粒物的消光系数受到相对湿度的显著影响。在相对湿度比 较高的情况下, 水溶性气溶胶颗粒能够吸湿膨胀, 消光系 数可以增大数倍, 故本文利用平均相对湿度数据对污染物 浓度数据进行湿度订正。

同时，考虑到 $\mathrm{AOD}$ 是垂直方向上消光系数的积分，而 $\mathrm{PM}_{2.5}$ 和 $\mathrm{PM}_{10}$ 的测量以及API数据都代表地面空气质量。通 常情况下，假定气溶胶消光系数垂直方向上按指数分布， 光学厚度为消光系数垂直方向上的积分, 而地面消光系数 与能见距离具有反比关系, 因此本文利用气象站的能见度 数据来进行气溶胶垂直分布订正。

最后分季节分别进行模型分析, 在指数函数、对数函 数、幂函数、线性和一元二次方程 5 种模型中, 根据 $\mathrm{R}^{2}$ 相 应地选择各季节最佳模型,并对不同模型结果进行精度验 证, 最终 $\mathrm{PM}_{10}$ 和 $\mathrm{PM}_{2.5}$ 的污染物浓度分布特征。

对于 $\mathrm{O}_{3} 、 \mathrm{SO}_{2} 、 \mathrm{NO}_{2} 、 \mathrm{CO}$ 等污染物浓度, 由于目前针 对这类污染物设计的高光谱传感器空间分辨率有限, 本文 采用克里金插值法 (Kriging) 对这几种污染物浓度进行处 理分析。

污染物浓度数据获取的操作流程如图1所示。

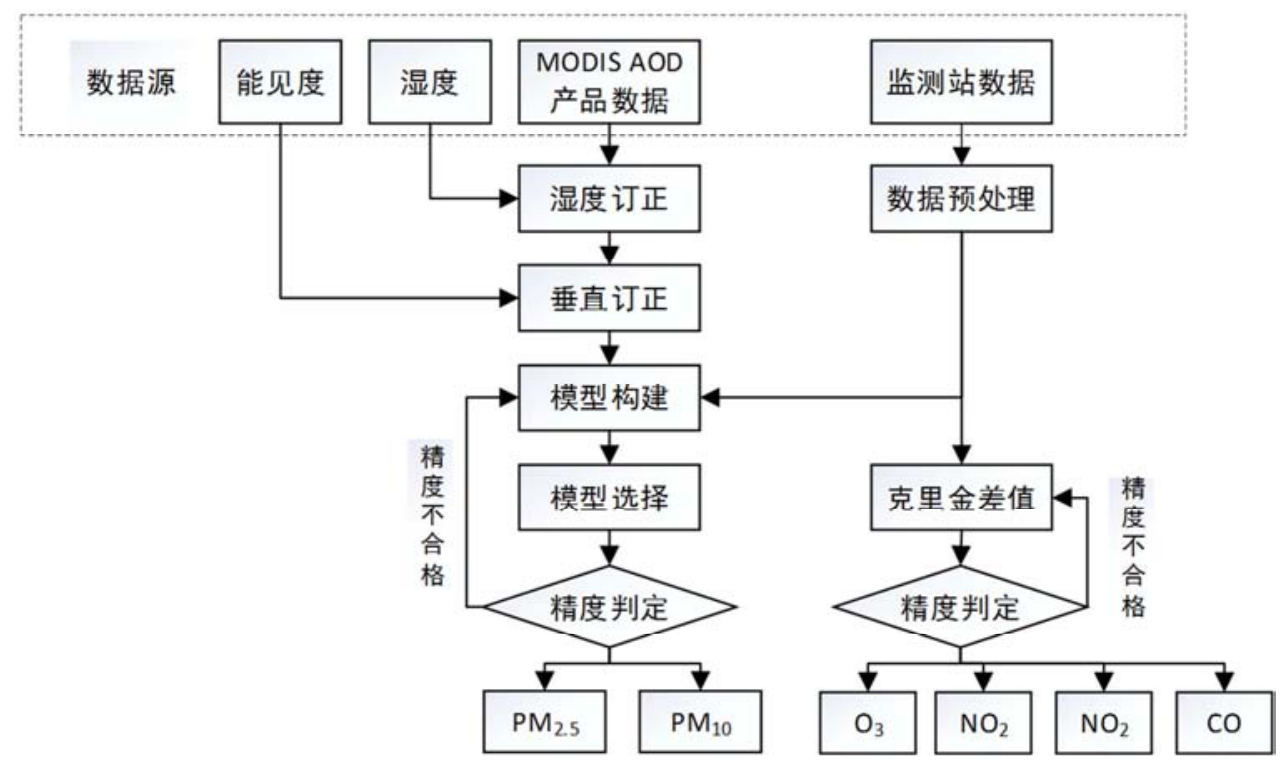

图1 数据处理流程。 


\section{3. 克里金插值方法}

克里金插值法是地统计学的主要内容之一, 从统计意 义上说, 是从变量相关性和变异性出发, 在有限区域内对 区域化变量的取值进行无偏、最优估计的一种方法 [13]。

假设区域化变量 $Z(x)$ 满足二阶平稳假设和本征假设, 其数学期望为 $m$, 协方差函数 $C(h)$ 及变异函数 $\gamma(h)$ 存在 [14]。即:

$$
\begin{gathered}
E[Z(x)]=m \\
C(h)=E[Z(x) Z(x+h)]-m^{2} \\
\gamma(h)=\frac{1}{2} E[Z(x)-Z(x+h)]^{2}
\end{gathered}
$$

假设在待估计点 $x_{0}$ 的临域内共有 $n$ 个实测点, 即 $x_{0}, x_{1}, \cdots, x_{n}$ 。则普通克里金法的插值公式为:

$$
Z^{*}\left(x_{0}\right)=\sum_{i=1}^{n} \lambda_{i} z\left(x_{i}\right)
$$

式中, $Z^{*}\left(x_{0}\right)$ 为带骨架污染物浓度栅格值; $n$ 为用于 空气湿度差值站点数; $z\left(x_{i}\right)$ 为第 $i$ 个站点平均污染物浓度
值; $\lambda_{i}$ 为赋予第 $i$ 个站点平均污染物浓度的一组权重系数。 引入拉格朗日系数 $\mu$ 进行推导可得:

$$
\begin{gathered}
\sum_{i=1}^{n} \lambda_{i} z\left(x_{i}-x_{j}\right)+\mu=x_{j}-x_{0}, j=1, \ldots, n \\
\sum_{i=1}^{n} \lambda_{i}=1
\end{gathered}
$$

因此，权重系数 $\lambda_{i}(i=1, \ldots, n)$ 和拉格朗日乘数 $\mu$ 可由 以上式 (5) (6)求得, 从而由式 (4) 可得研究区域内任意 点的插值估计。

\section{3. 数值分析}

\section{1. 北京市污染物时间特征分析}

\subsection{1. 季节性特征分析}

2014-2017年不同季度间, 北京城区的CO、 $\mathrm{NO}_{2} 、 \mathrm{SO}_{2} 、$ $\mathrm{PM}_{10}$ 和 $\mathrm{PM}_{2.5}$ 的浓度有着大致相似的变化趋势, 且受供暖 期的影响, 每年的第一、四季度浓度较高, 第二、三季度 浓度较低; 而 $\mathrm{O}_{3}$ 却与之相反, 呈现第一、四季度浓度低, 第二、三季度浓度高的特征, 且冬夏季的差值有3-4倍。

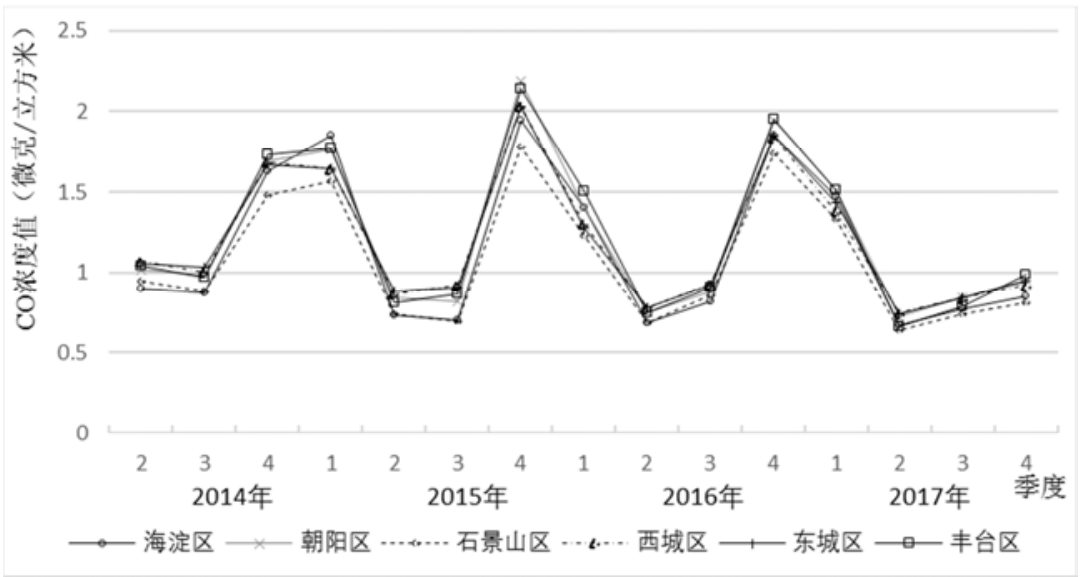

图2 CO浓度季节性特征变化图。

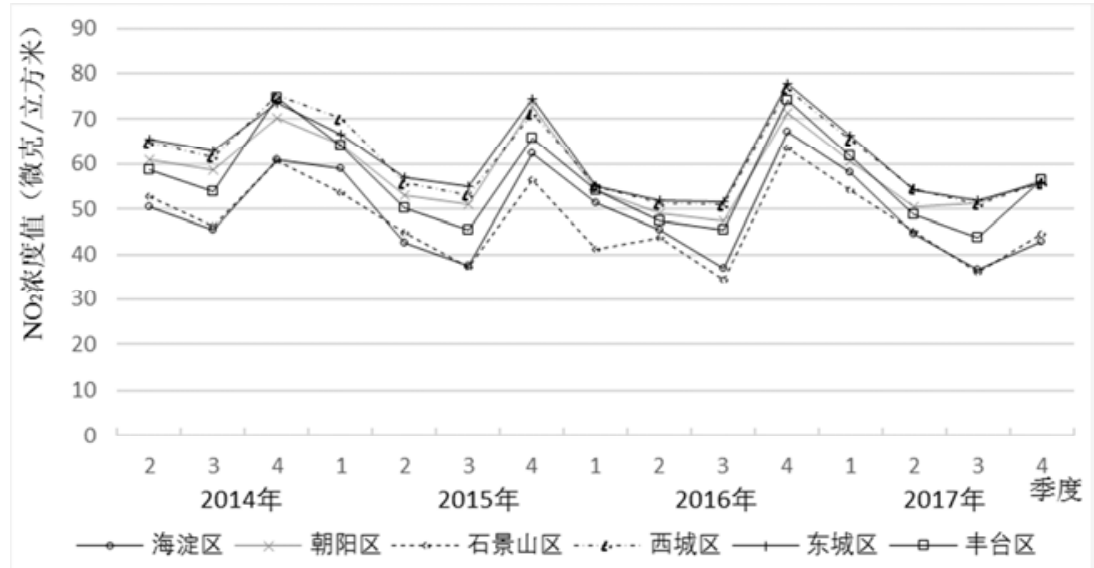

图3 $\mathrm{NO}_{2}$ 浓度季节性特征变化图。 


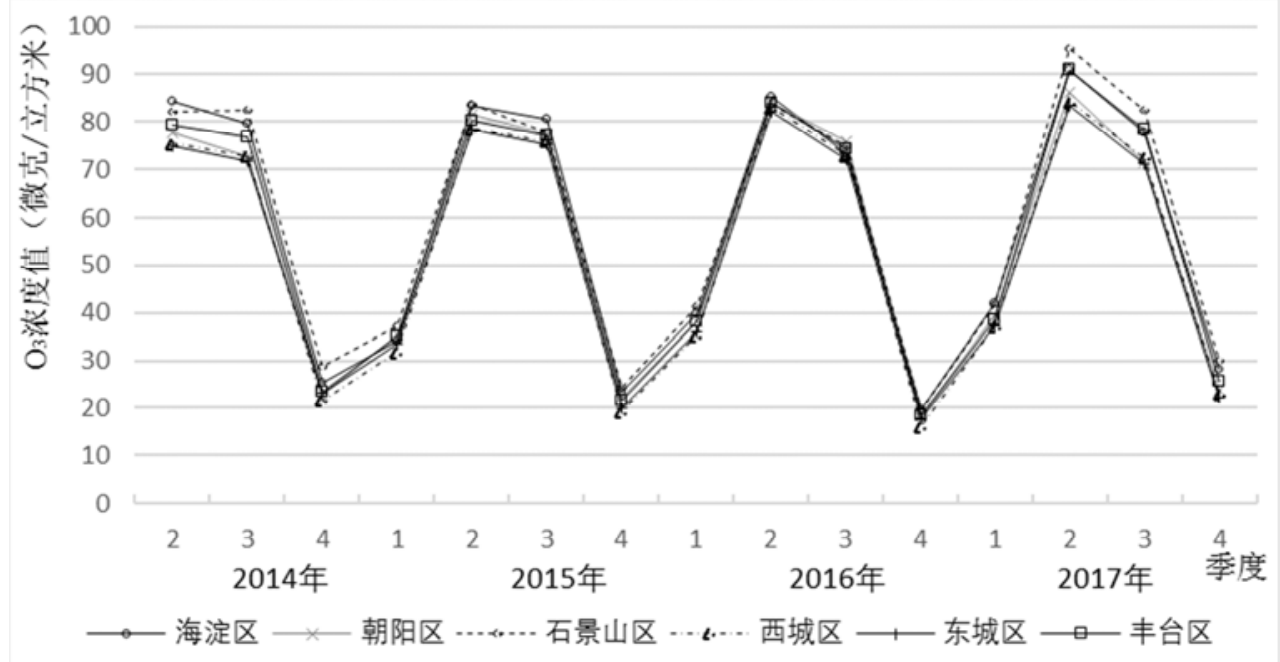

图4 $\mathrm{O}_{3}$ 浓度季节性特征变化图。

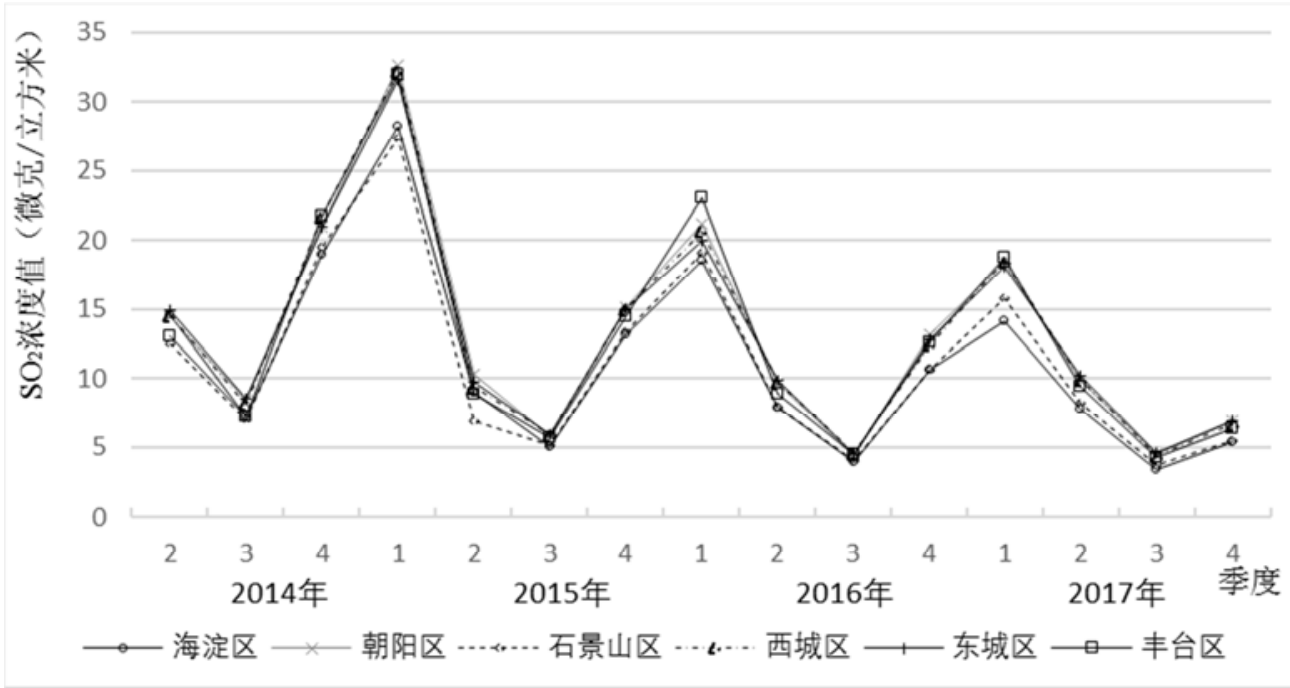

图5 $\mathrm{SO}_{2}$ 浓度季节性特征变化图。

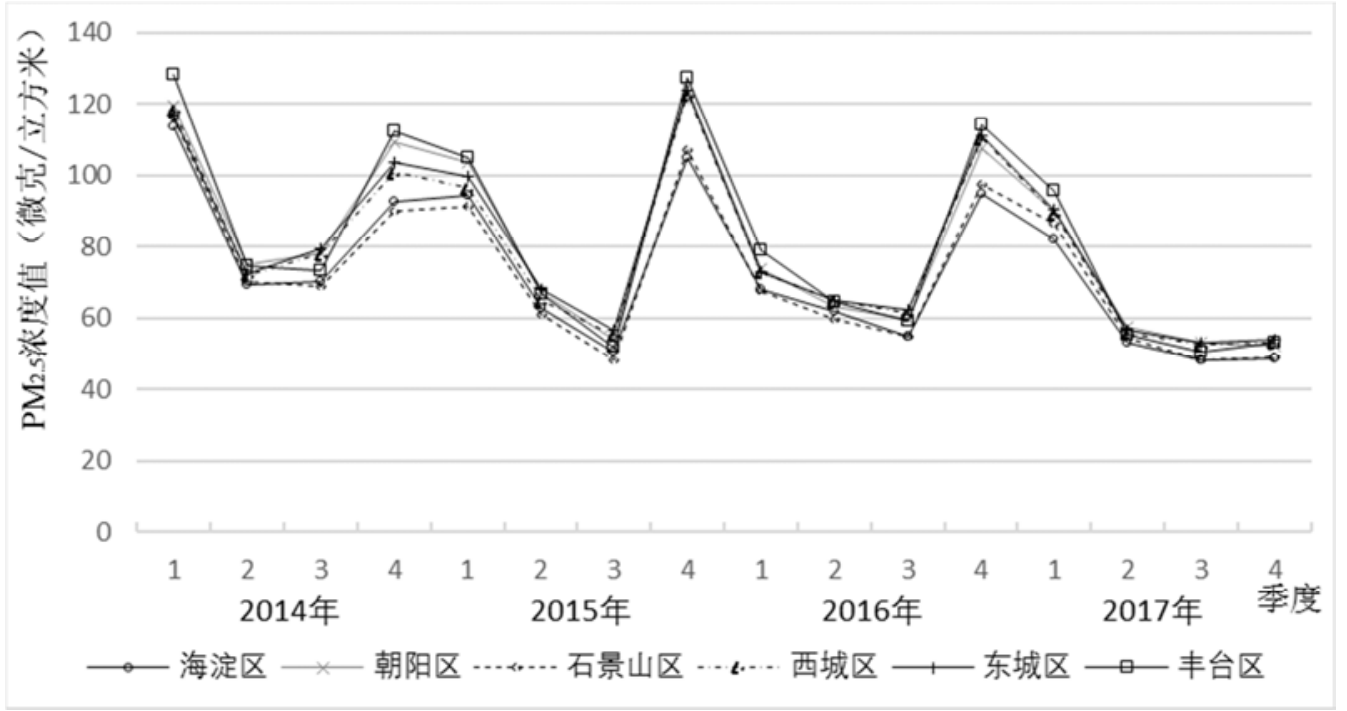

图6 $\mathrm{PM}_{2.5}$ 浓度季节性特征变化图。 


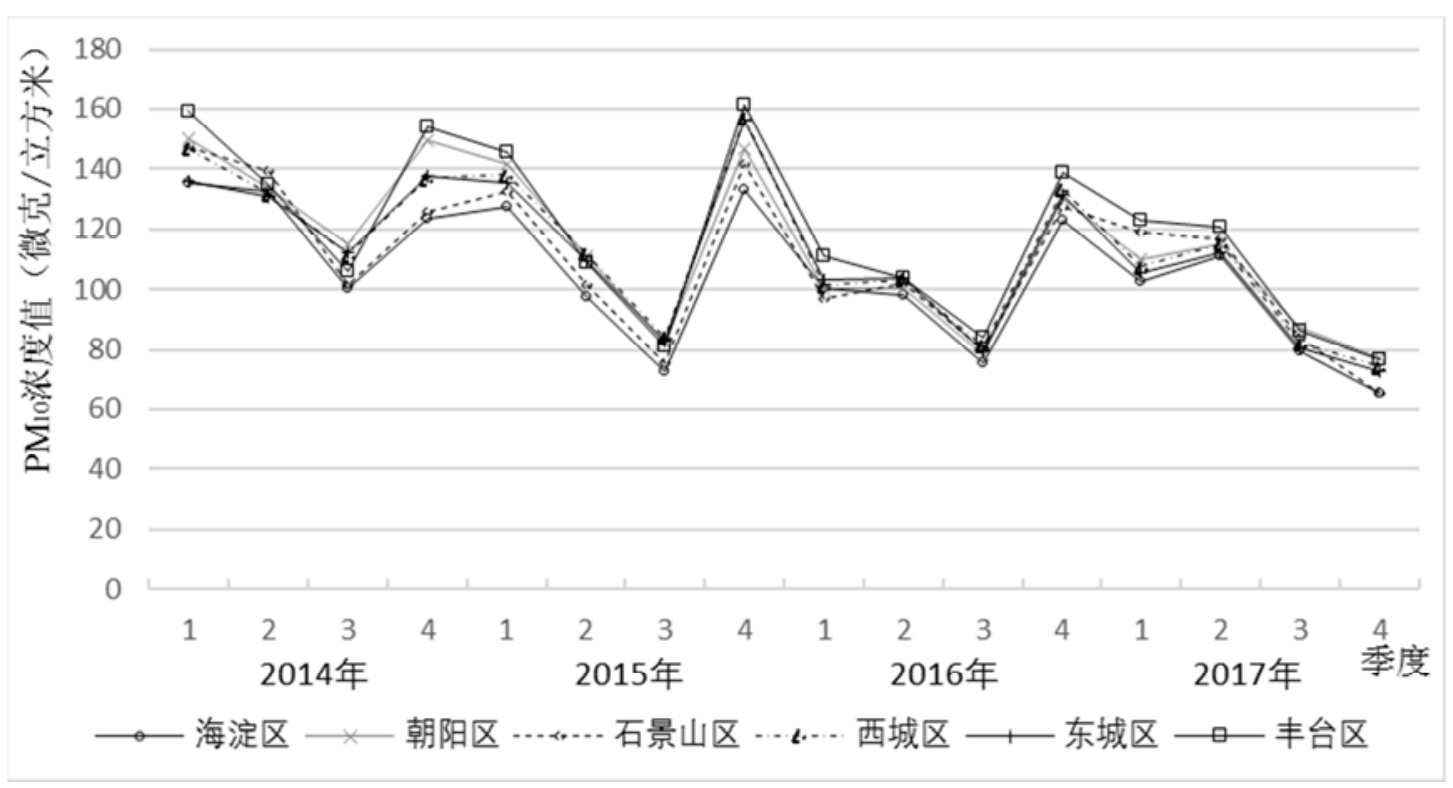

图7 $\mathrm{PM}_{10}$ 浓度季节性特征变化图。

\subsection{2. 年度特征分析}

随着近年来大气污染治理措施的实施, 2014-2017年 间, 大多数污染物浓度有下降趋势, 特别是 $\mathrm{SO}_{2} 、 \mathrm{PM}_{2.5}$ 和 $\mathrm{PM}_{10}$ 下降趋势显著。CO浓度均在2015年达到了一个小的
峰值, 而后呈递减趋势。与之相反的是, 北京城区的 $\mathrm{O}_{3}$ 浓度在 2015 年达到了一个小的低谷, 而后平缓上升。在PM 等污染物治理已见成效的同时, 北京开始面对严峻的臭氧 问题。

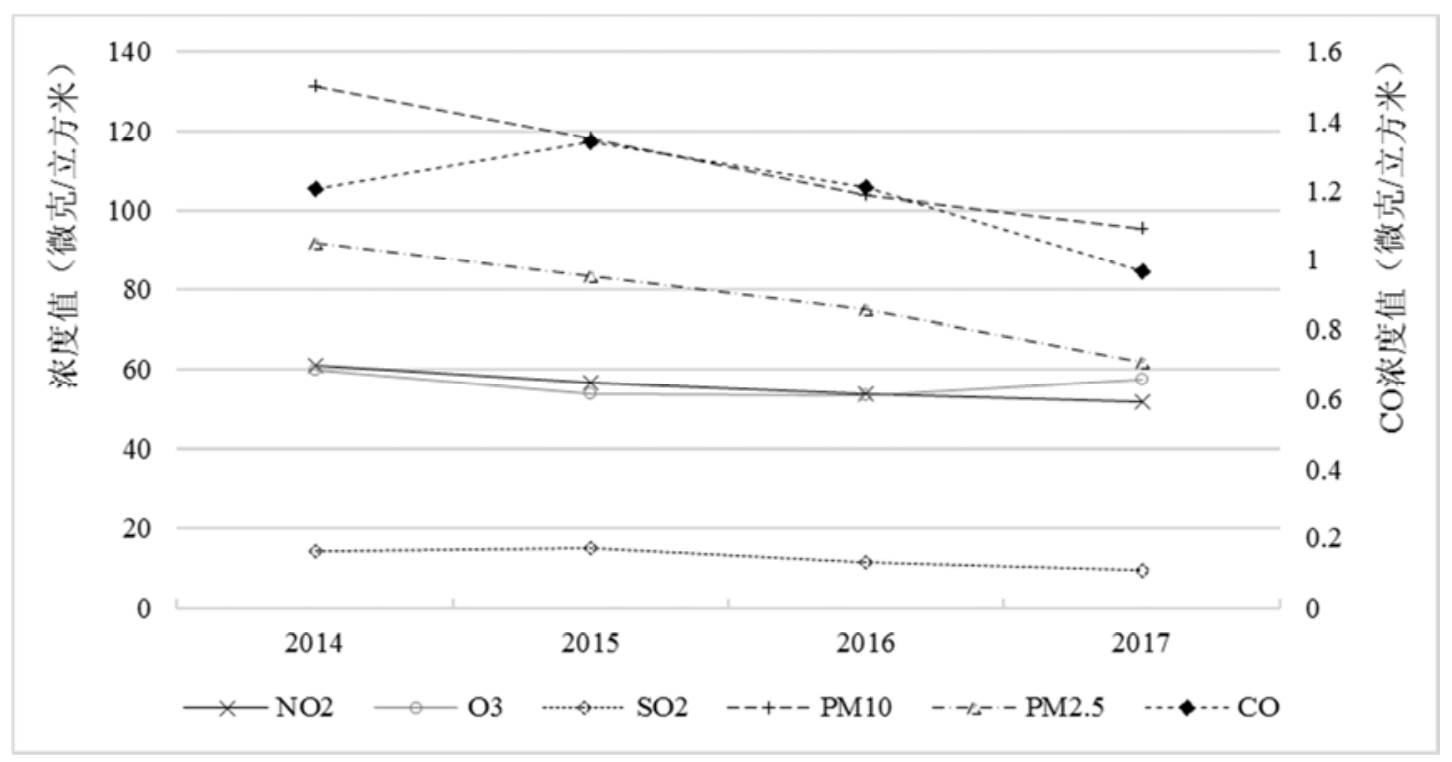

图8 各类污染物浓度季年度特征变化图。

\section{2. 北京市污染物空间特征分析}

从图2-图7也可以间接的发现, 不同季节的 $\mathrm{CO}$ 污染物 浓度也呈现空间性差异，一季度海淀区和朝阳区浓度较大; 二、三季度, 西城区和东城区浓度较大; 朝阳区和丰台区 次之; 四季度, 朝阳区和丰台区浓度较大。而石景山区一 年中一直保持浓度最低。其他污染物浓度的空间差异对季 节性不敏感, 表 1 给出了北京城区中污染物浓度最高和最 低的行政区, 从表中可以发现, 就空气质量而言石景山区 最为宜居。
表1 各区县污染物浓度程度表。

\begin{tabular}{lll}
\hline 污染物 & 浓度最高 & 浓度最低 \\
\hline $\mathrm{NO}_{2}$ & 东城区、西城区 & 石景山区 \\
$\mathrm{O}_{3}$ & 海淀区、石景山区 & 西城区 \\
$\mathrm{SO}_{2}$ & 朝阳区、丰台区 & 石景山区 \\
$\mathrm{PM}_{10}$ & 丰台区 & 海淀区 \\
$\mathrm{PM}_{2.5}$ & 丰台区 & 海淀区、石景山区 \\
\hline
\end{tabular}

由于篇幅所限, 图9-14给出了各类污染物浓度最高时 期, 其空间分布特征。其中 $\mathrm{CO} 、 \mathrm{NO}_{2} 、 \mathrm{PM}_{2.5}$ 和 $\mathrm{PM}_{10}$ 的峰 
值均出现在 2015 年第四季度, $\mathrm{SO}_{2}$ 的峰值出现在 2015 年第 一季度, $\mathrm{O}_{3}$ 的峰值出现在 2017 年第二季度。

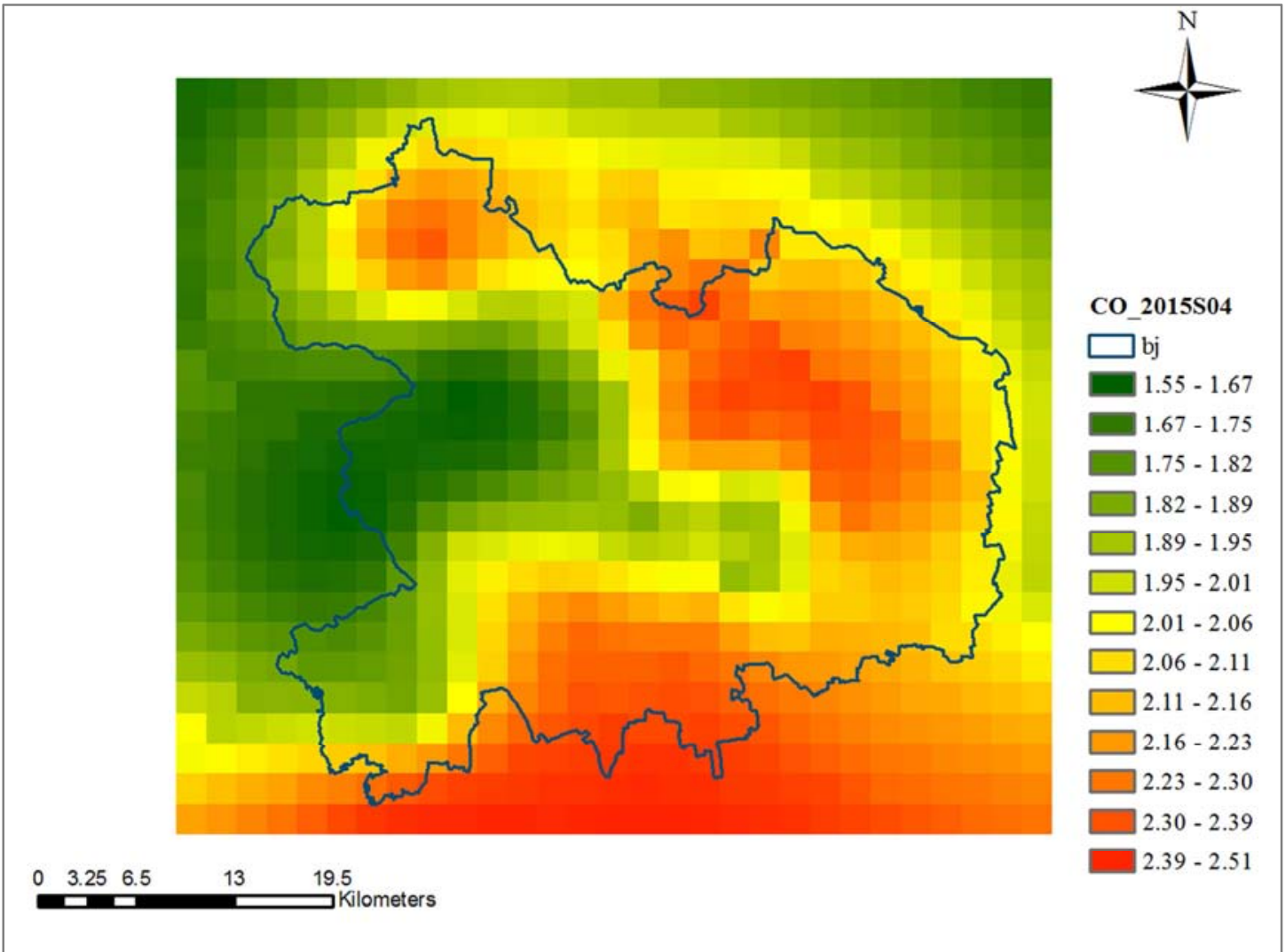

图9 2015年第4季度北京城区CO浓度分布图。

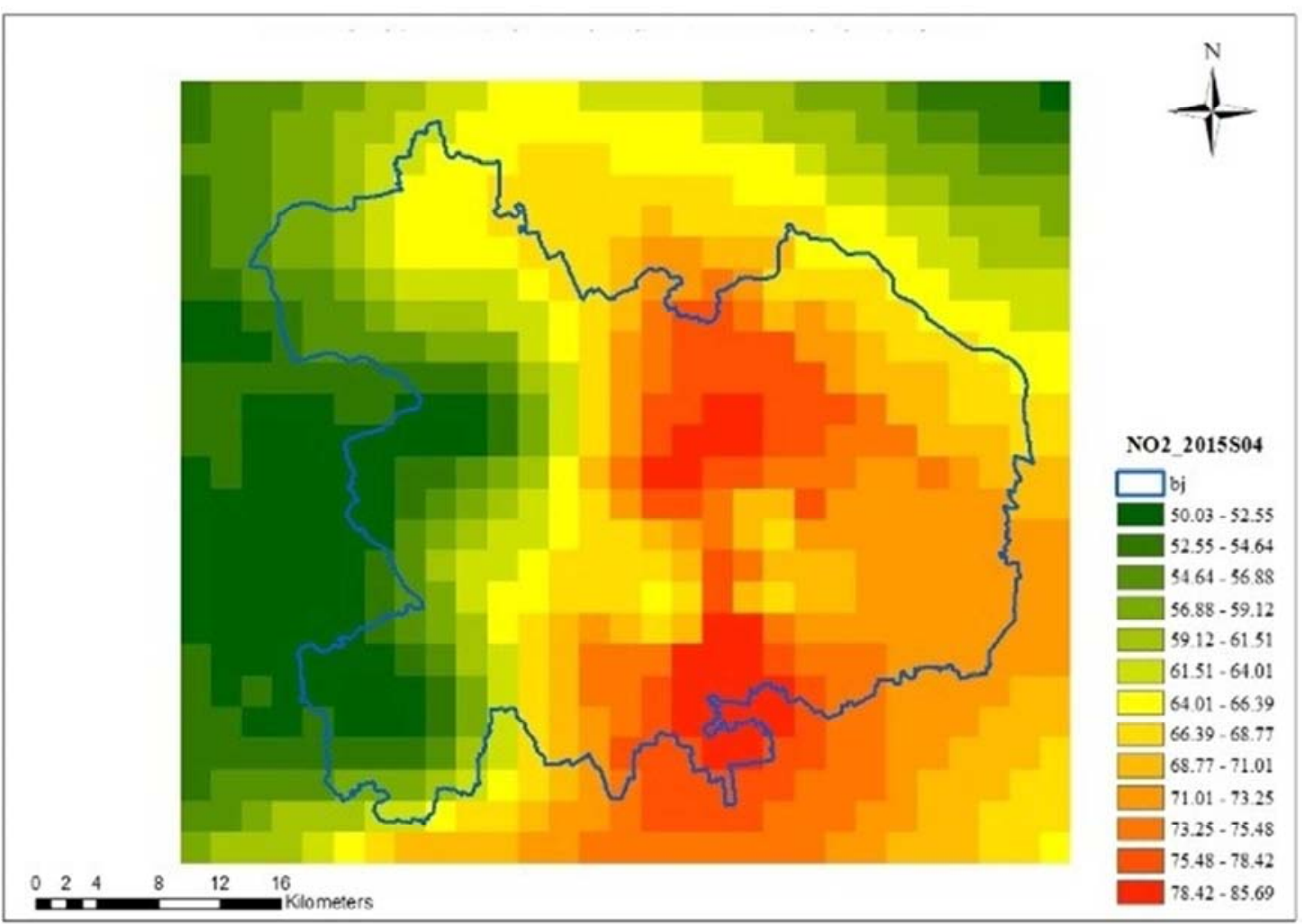

图10 2015年第4季度北京城区 $\mathrm{NO}_{2}$ 浓度分布图。 


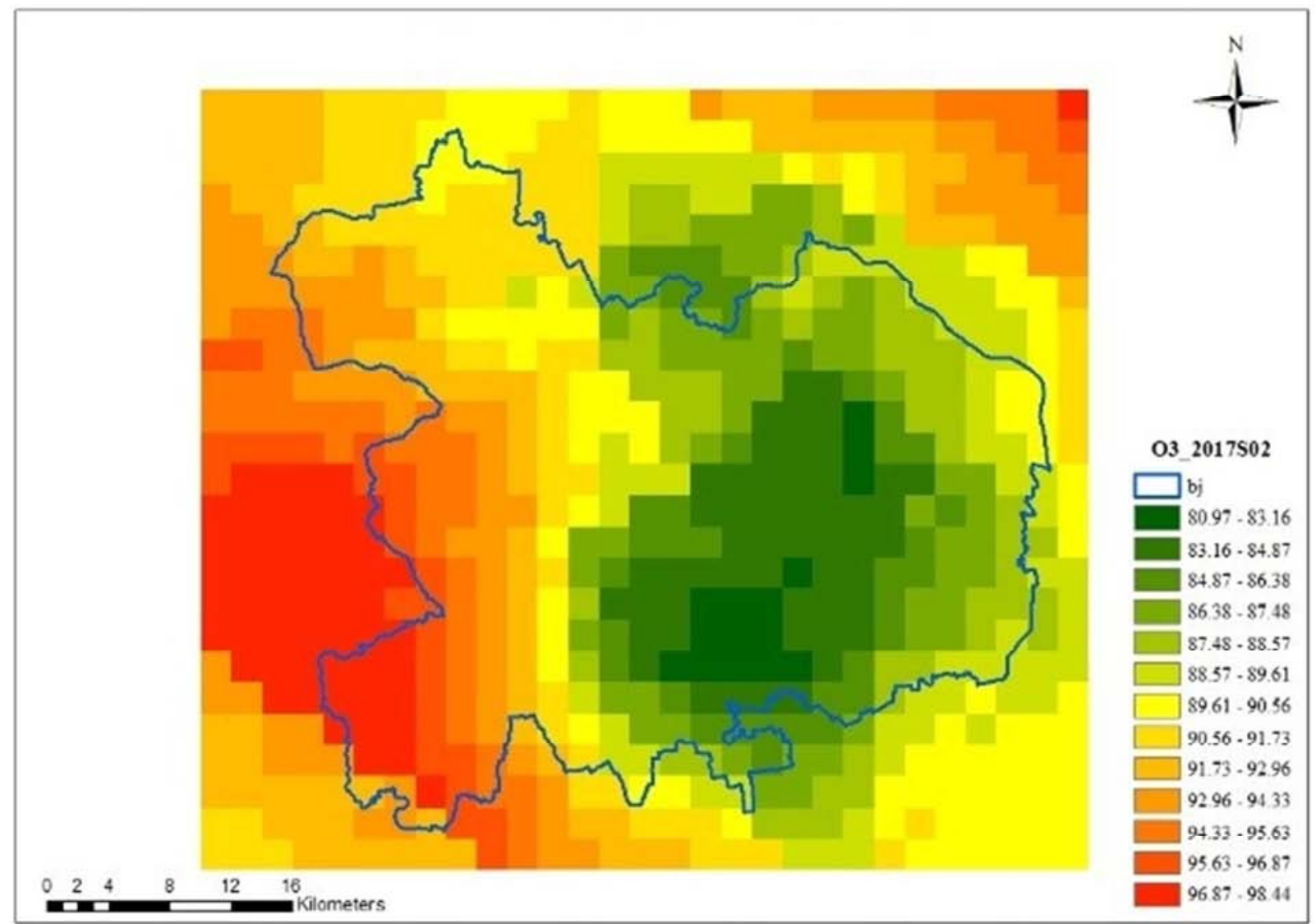

图11 2017年第2季度北京城区 $\mathrm{O}_{3}$ 浓度分布图。

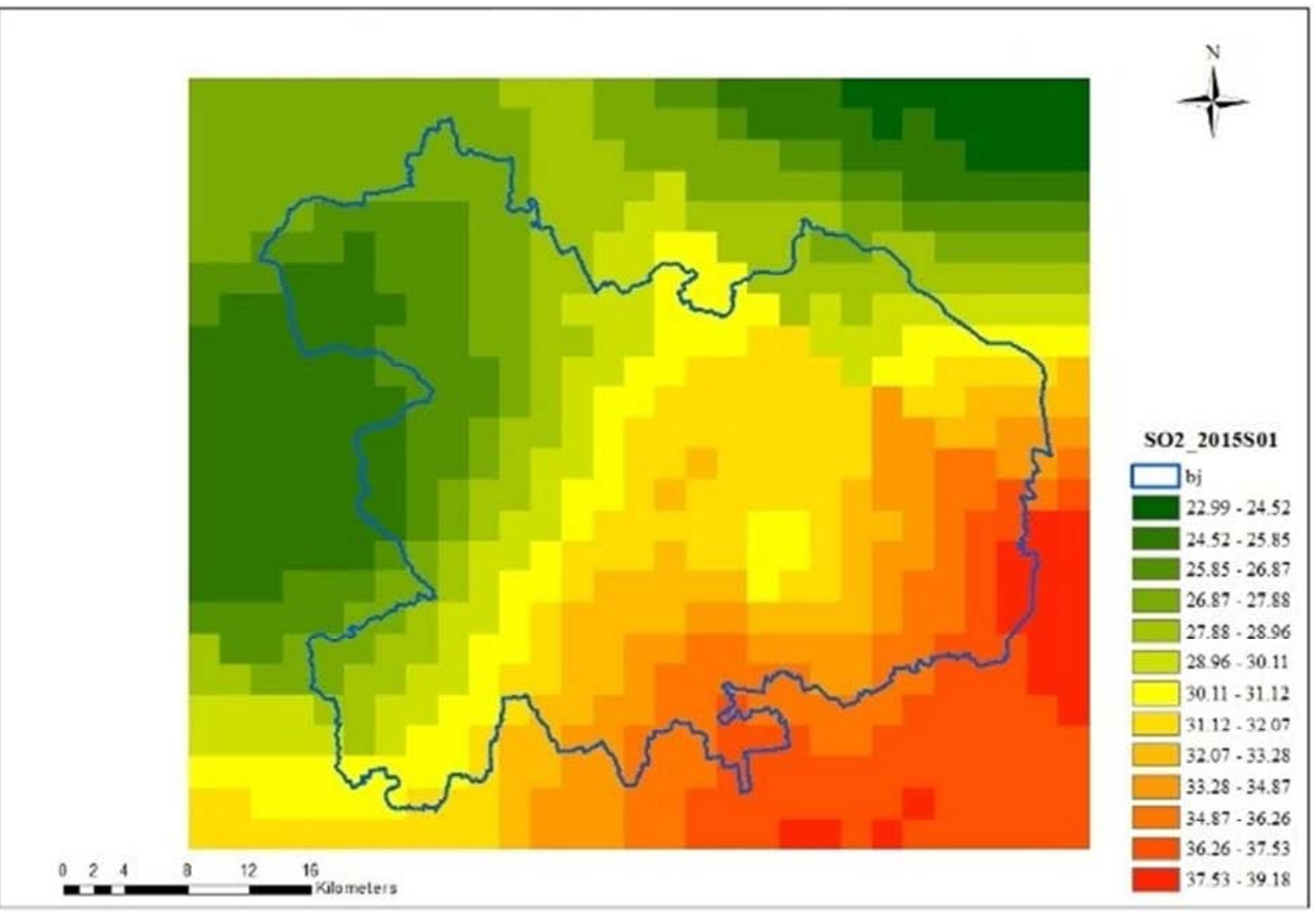

图12 2015年第1季度北京城区 $\mathrm{SO}_{2}$ 浓度分布图。 


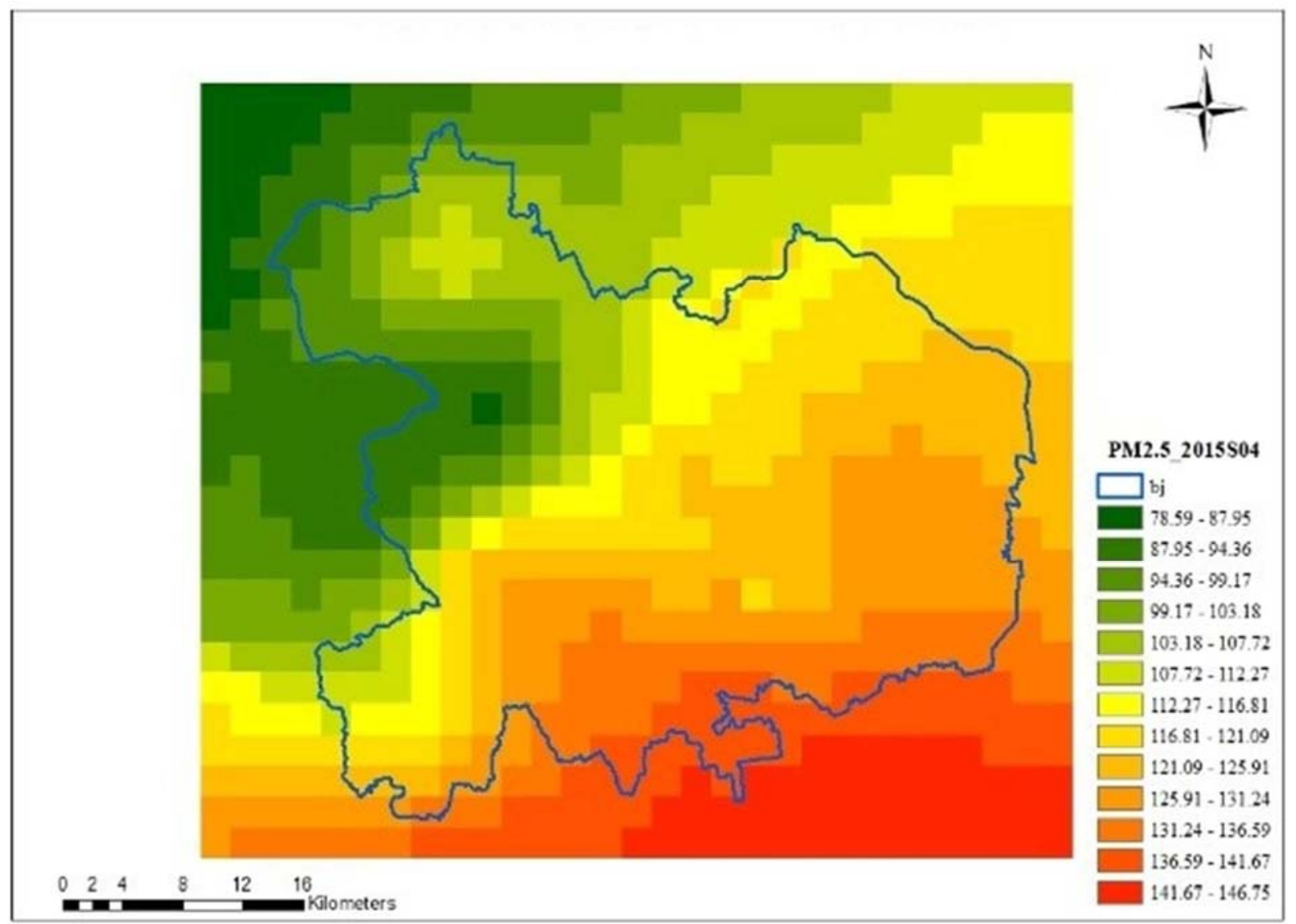

图13 2015年第4季度北京城区 $\mathrm{PM}_{2.5}$ 浓度分布图。

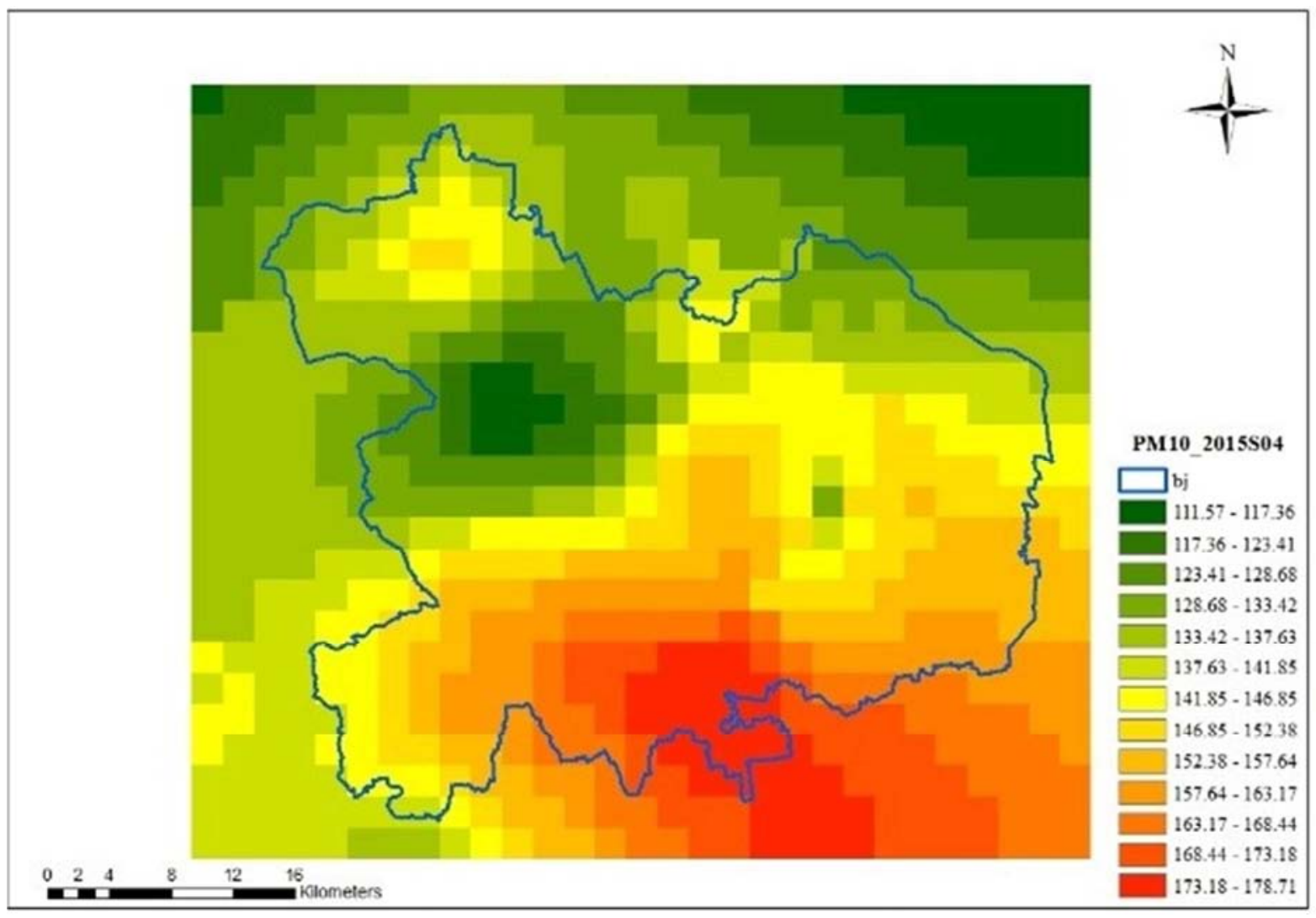

图14 2015年第4季度北京城区 $\mathrm{PM}_{10}$ 浓度分布图。 


\section{4. 结论}

本文利用数据反演和克里金插值方法, 以遥感影像数 据和地面气象站监测数据为基础, 深入分析 2014 年-2017 年北京城区的主要污染物浓度特征。

通过分析发现, 近年来大气污染治理措施推进下, 北 京城区大多数污染物浓度有下降趋势, 特别是 $\mathrm{SO}_{2} 、 \mathrm{PM}_{2.5}$ 和 $\mathrm{PM}_{10}$ 下降趋势显著, 但臭氧问题开始突出; 不同区县的 $\mathrm{CO}$ 浓度的存在季节性差异，其他污染物浓度的空间差异 对季节性不敏感; 就空气质量而言, 就空气质量而言石景 山区最为宜居。

\section{致谢}

本文为北京市财政项目《北京城市能源系统气候变化 适应性分析技术研发》(编号: PXM2018_178215_000004)、 课题《基于路网车流量的通州及北三县机动车污染控制研 究》、北京市委组织部优秀人才项目（编号: 2016400685627G230）的研究成果之一。

\section{参考文献}

[1] 严心田,李楠,余欢,等.典型会议期间污染调控对城市空气质 量影响分析[J].南京理工大学学报,2018,42(06):739-746.

[2] 王景云,张红日,赵相伟,等.2012-2015年北京市空气质量指 数变化及其与气象要素的关系 $[\mathrm{J}]$. 气象与环境科 学,2017,40(04):35-41.

[3] Hoff, Raymond M,Christopher, Sundar A. Remote Sensing of Particulate Pollution from Space: Have We Reached the Promised Land? [J]. Journal of the Air \& Waste Management Association, 2009, 59(6).
[4] Randall V. Martin. Satellite remote sensing of surface air quality [J]. Atmospheric Environment, 2008, 42(34).

[5] Wang J, Christopher S A. Intercomparison between satellite -derived aerosol optical thickness and PM2.5 mass: Implicationsfor air quality studies[J]. Geophysical Research Letters, 2003,30(21): 267-283.

[6] Donkelaar A V, Martin R V, Brauer M et al. Global estimates of ambient fine particulate matter concentrations from Satel-lite-based Aerosol Optical Depth: Development and application [J]. Environmental Health Perspectives, 2010, 118(6): 847-855.

[7] 赵柏林,张茫菲,高国明.我国大气气溶胶光学厚度的特性[J]. 气象学报,1986,44(2):235-241.

[8] 刘大锰,黄杰,高少鹏,等.北京市区春季交通源大气颗粒 物 的污染水平及其影响因素 [J]. 地学前缘,2006,13(2):228-233.

[9] 顾吉林, 汤宏山, 刘沝, 等. 大连市大气污染物质量浓度 与气溶胶光学厚度的相关性分析 [J/OL]. 地理科学. http://kns.cnki.net/kcms/detail/22.1124.P.20190325.0959.002. html

[10] 李慧杰,王秀兰,王计平,李梦捷,杨晓潚.2013-2017年间京 津冀地区空气质量及影响因素分析 [J].环境监测管理与技 术,2019, 3:1-6.

[11] 王斌.利用空气污染指数(API)分析我国空气污染的区域时 空变化特征[D].青岛:海洋大学,2008.

[12] 李祥,彭玲,池天河,李浩川,徐逸之.北京市空气质量时空特 征分析[J].测绘通报,2016(09):47-51.

[13] 邓岳川,谷双喜.克里金插值的多路径误差空间分布特征 [J]. 测绘科学,2018,43(04):17-23.

[14] 周体鹏. 基于克里金插值法的昆明市PM2.5预测[D]. 昆明: 云南大学,2016. 